\title{
A EVOLUÇÃO DOS DIREITOS TRABALHISTAS DAS MULHERES SOB O PRISMA DOS LIMITES DA FLEXIBILIZAÇÃO NO DIREITO DO TRABALHO
}

\section{THE EVOLUTION OF WOMEN'S LABOR RIGHTS UNDER THE PRISM OF THE LIMITS OF FLEXIBILIZATION IN THE LAW OF LABOR}

\author{
Fernanda Heloisa Macedo Soares ${ }^{1}$ \\ Elisangela Marcari ${ }^{2}$ \\ Josimar Rodrigo da Fonseca ${ }^{3}$
}

\begin{abstract}
Resumo: O objetivo principal do presente trabalho foi o de analisar a evolução histórica dos direitos trabalhistas da mulher, levando em consideração as garantias conquistadas ao longo do tempo e seus reflexos na atual legislação trabalhista brasileira. Destarte, buscou-se elencar o que a CLT prevê como direitos para a trabalhadora, levando em consideração a saúde e as questões que envolvem a maternidade. Ademais, foram analisados o contexto histórico e a conceituação do instituto da flexibilização, elencando ainda suas formas e as principais correntes doutrinárias. Por fim, ponderou-se sobre os limites da flexibilização frente os direitos trabalhistas das mulheres, colacionando-se decisões do Tribunal Superior do Trabalho. A metodologia utilizada foi o da pesquisa bibliográfica, que por intermédio do levantamento bibliográfico sobre o tema foi possível constatar informações e subsídios para o desenvolvimento do tema proposto. Com base no estudo documental e bibliográfica conclui-se que existem alguns pontos falhos a serem revistos e melhorados para melhor aplicação das diretrizes da Lei de Cotas.
\end{abstract}

PALAVRAS-CHAVES: Direito do Trabalho. Direitos da Mulher. Flexibilização.

Abstract: The main objective of this study was to analyze the historical evolution of women's labor rights, taking into account the guarantees earned over time and its effects on current Brazilian labor legislation. Thus, we sought to list what the CLT provides as rights for the worker, taking into account the health and issues surrounding maternity. In addition, we analyzed the historical context and the conceptualization of the flexibilization institute, and it also lists its forms and main doctrinal currents. Finally, we considered the limits of flexibilization, against women's labor rights, collating decisions of the Superior Labor Court. The methodology used was the bibliographical research, that through the bibliographical survey on the subject it was possible to verify information and subsidies for the development of the proposed theme. Based on the documentary and bibliographic study it is concluded that there are some flaws to be reviewed and improved for better application of the guidelines of the Quota Law.

KEYWORDS: Labor Law. Women rights. Flexibilization.

\section{INTRODUÇÃO}

Objetivando a análise da evolução das

normas trabalhistas protecionistas às mulheres $\mathrm{e}$ identificando até que ponto que as mesmas permitem a flexibilização dos direitos garantidos após longos anos de lutas por melhorias, a pesquisa visa pontuar os limites da flexibilização frente aos direitos trabalhistas deste contingente.
Embora seja clara a evolução da proteção dada ao trabalho da mulher, é relevante ressaltar que a legislação deve acompanhar cada dia mais sua inserção no mercado de trabalho, respeitando e valorizando o trabalho desenvolvido pelas mesmas. Portanto, é dever do legislador garantir formas de proteção às garantias conquistadas.

\footnotetext{
${ }^{1}$ Possui graduação em Direito pelo Centro Universitário Euripedes de Marília (2002) e mestrado em Direito pelo Centro Universitário Euripedes de Marília (2010). Atualmente é professor adjunto da Associação Educativa Evangélica, advogado - Ordem dos Advogados do Brasil - Seção de Goiás e advogado Ordem dos Advogados do Brasil - Conselho Seccional de São Paulo. Tem experiência na área de Direito, com ênfase em Direito Civi

${ }^{2}$ Mestranda em Teoria Geral do Direito pelo Univem (Fundação Euripedes Soares da Rocha). Especialista em DIREITO TRIBUTÁRIO pela UNAMA. Possui graduação em DIREITO pelo Centro Universitário da Grande Dourados (1999). Atualmente Advogada e professora na - FASIP - Faculdade de Sinop. Tem experiência na área Jurídica como Advogada desde 2006.

${ }^{3}$ Bacharel em Direito pela Faculdade Evangélica de Goianésia. Advogado.
} 
O presente trabalho pauta-se no objetivo de delinear uma linha histórica da evolução dos direitos protecionistas ao trabalho da mulher, levando em consideração a influência e o reflexo do direito internacional na elaboração da atual legislação trabalhista brasileira.

No que tange à problemática envolvida pelo tema, foram tratados dois problemas com maior ênfase. $O$ primeiro se baseia na construção de uma sociedade que busca resguardar os direitos de seus cidadãos; as leis trabalhistas que protegem as mulheres são suficientes dentro o contexto jurídico brasileiro para proteger as trabalhadoras? O segundo enfoca que considerando os limites da flexibilização do Direito do Trabalho, qual a importância do princípio da proteção para resguardar os direitos da mulher?

Enquanto o objetivo geral foi o de estudar a evolução das normas trabalhistas protecionistas, um dos objetivos específicos consiste em avaliar esta evolução, comparando com o amparo que as mulheres trabalhadoras recebem através das Convenções e Resoluções da Organização Internacional do Trabalho.

Além disto, outro objetivo específico foi de ponderar sobre o instituto da flexibilização no Brasil, pontuando o conceito, as correntes doutrinárias e sua aplicabilidade dentro do panorama jurídico trabalhista. Isto posto, também procurou-se entender até que ponto a flexibilização afeta a mulher inserida no mercado de trabalho.

A busca por uma sociedade mais justa e igualitária é grande em nossa sociedade.
Apesar de evidentes, as desigualdades que permeiam o mundo continuam sendo ignoradas e lançadas à margem das comunidades e centros urbanos como se o Estado não tivesse o dever de intervir e zelar pelos direitos insculpidos na Carta Magna de 1988 e na Consolidação das Leis Trabalhistas. Dessa forma, é preciso preservar o direito da mulher frente aos riscos da flexibilização utilizada de forma abusiva.

A temática do presente trabalho foi abordada com base na pesquisa documental realizada em livros, artigos científicos e dissertações que ajudaram a compor o referencial desta pesquisa. Destarte, foi utilizado o método de pesquisa bibliográfica que se trata da fase inicial da pesquisa, onde se busca o levantamento bibliográfico sobre o tema, com o escopo de identificar informações e subsídios para definição dos objetivos, determinação do problema e definição dos tópicos do referencial teórico.

$$
\text { Com o intuito de otimizar o }
$$
desenvolvimento da pesquisa, para a explanação do tema da melhor forma didática, o presente trabalho foi dividido em três tópicos que versam de maneira sistemática as questões envolventes ao tema.

Buscou-se no primeiro momento o estudo da legislação protecionista ao trabalho da mulher. Assim, foi realizado o estudo sobre o contexto histórico, as lutas e acontecimentos em busca de leis que garantissem respaldo às mulheres que desejavam ingressar no mercado de trabalho. Além dos acontecimentos no âmbito internacional, foram elencados também os principais marcos históricos nacionais e os 
principais fundamentos para a proteção do trabalho da mulher.

Por sua vez, no segundo momento foi destinado a tratar sobre o instituto da flexibilização, desde a conceituação até sua aplicação prática. Além do contexto histórico, buscou-se a interpretação das modalidades de flexibilização e das principais correntes doutrinárias inerentes ao tema.

Por fim, foi destinado a ponderar sobre a flexibilização frente à Constituição Federal de 1988. O principal intuito foi o de elencar as possibilidades constitucionais que $\mathrm{O}$ empregador tem para flexibilizar direitos trabalhistas, observando sempre os limites que o próprio texto constitucional impõe.

Assim, foram colacionadas jurisprudências acerca da proibição da flexibilização de direitos trabalhistas referentes ao trabalho da mulher, caso versem sobre garantias à maternidade ou sobre a sua saúde, no afã de proteger a trabalhadora.

\section{LEGISLAÇÃO PROTECIONISTA AO TRABALHO DA MULHER}

Para que seja feita uma análise da evolução da legislação protecionista inerente ao trabalho da mulher no âmbito do ordenamento jurídico brasileiro, faz-se necessário entender o desenvolvimento das leis trabalhistas brasileiras.

Ao compulsionar a doutrina majoritária, compreende-se que o Direito do Trabalho nem sempre teve o respaldo jurídico que tem atualmente. Martins (2014) salienta que a palavra trabalho vem do latim tripalium, instrumento de tortura de três paus ou uma canga que pesava sobre os animais. Assim, a imagem que se tinha era de algo penoso, sendo talvez um das principais razões de ter sido a escravidão como uma das primeiras formas de trabalho. Vale ressaltar que não pode ser considerado trabalho o ato de ser proprietário de outro ser humano.

escravidão é a primeira forma de trabalho conhecida. Nesta fase, não encontramos direitos, pois os escravos não eram considerados pessoas capazes de adquiri-los". De tal modo, embora fosse uma relação desumana, a escravidão foi o primeiro passo para as relações de emprego e de ofício, quando começaram a surgir conflitos entre este e o capital.

De acordo com Jorge Neto e Cavalcante (2010), o marco inicial das normas de proteção ao trabalho dos homens e das mulheres foi a Revolução Industrial. Os relatos históricos demonstram uma exploração deste utilizando mulheres e crianças, com péssin dições de trabalho e de salário nesta épocia. cuncudo, vale ressaltar que antes da Revolução Industrial já havia outra forma de trabalho, como disposto a seguir.

Nesse sentido, Marques (2013, p. 03) verbera que

Com a evolução das sociedades, surgem as primeiras formas de trabalho, como a servidão, e em seguida as corporações de ofício. A principal causa econômica para o surgimento do direito do trabalho foi a Revolução Industrial do século XVIII, que determinou também o aparecimento da sociedade industrial e do trabalho assalariado. 
De forma mais detalhada, Nascimento (2014) ensina que três aspectos determinaram o surgimento da sociedade industrial, sendo eles econômicos, políticos e jurídicos. A rigor, o autor caracteriza a Revolução Industrial como principal causa econômica para a formação de uma sociedade que tinha a indústria cada vez mais expandida. Graças a este crescimento houve a substituição do trabalho escravo pelo assalariado, em larga escala.

No que tange aos aspectos políticos, Nascimento (2014, p. 44) aduz que "o mais importante foi a transformação do Estado Liberal e da plena liberdade contratual em Estado Neoliberalista". Já o aspecto jurídico está ligado ao fato dos trabalhadores terem reivindicado, por intermédio dos sindicatos, direitos de proteção e leis que coibissem os abusos dos empregadores, preservando o princípio da dignidade do homem no trabalho.

Corroborando com este entendimento, Martins (2014, p. 6) doutrina que

A Revolução Industrial acabou transformando o trabalho em emprego. Os trabalhadores, de maneira geral, passaram a trabalhar por salários. Com a mudança, houve uma nova cultura a ser apreendida e uma antiga a ser desconsiderada. [...] Constata-se, nessa época, que a principal causa econômica do surgimento da Revolução Industrial foi o aparecimento da máquina a vapor como fonte energética. [...] Com novos métodos de produção, a agricultura também passou a empregar um número menor de pessoas, causando desemprego no campo. Inicia-se, assim, a substituição do trabalho manual pelo trabalho com o uso de máquinas. Havia necessidade de que as pessoas viessem, também, a operar as máquinas não só a vapor, mas as máquinas têxteis, o que fez surgir o trabalho assalariado. Daí nasce uma causa jurídica, pois os trabalhadores começaram a reunir-se, a associarse, para reivindicar melhores condições de trabalho e de salários, diminuição das jornadas excessivas e contra a exploração de menores e mulheres.

$\mathrm{O}$ autor rechaça que nesta época, o trabalho adulto era substituído pelo das mulheres e pelos menores. O que se tinha, neste período, era que os próprios empresários preferiam o trabalho da mulher nas indústrias, pois elas aceitavam salários inferiores ao dos homens, contudo, desempenhavam o mesmo serviço.

Vale salientar que este foi apenas o primeiro grande marco na história do Direito do Trabalho em âmbito internacional com reflexos nos direitos trabalhistas do ordenamento jurídico brasileiro.

Delgado (2014, p. 83) leciona que "o Direito do Trabalho é produto do capitalismo, atado à evolução histórica desse sistema, retificando-lhe distorções econômico-sociais e civilizando a importante relação de poder que sua dinâmica econômica cria no âmbito da sociedade civil”.

Subtrai-se deste entendimento que as conquistas relacionadas ao Direito do Trabalho estão ligadas ao capitalismo e seu consequente poder transformador da sociedade. Assim, cumpre salientar que este ramo do Direito não serviu apenas ao sistema econômico deflagrado pela Revolução Industrial. Houve, portanto, outros fatores relevantes.

O surgimento da máquina a vapor foi um fato de suma relevância dentro do contexto histórico internacional. De acordo com Martins (2014, p. 6-7) 
“[...] houve a instalação das indústrias onde existisse carvão, como ocorreu na Inglaterra. [...] O trabalhador prestava serviços em condições insalubres, sujeito a incêndios, explosões, intoxicação por gases, inundações, desmoronamentos, prestando serviços por baixos salários e sujeito a várias doenças decorrentes dos gases, da poeira, do trabalho em local encharcado, principalmente a tuberculose, a asma e a pneumonia. [...] Certos trabalhadores eram comprados e vendidos com seus filhos. Os trabalhadores ficavam sujeito a multas, que absorviam seu salário. Isso só terminou por meio dos decretos parlamentares de 1774 e 1779, quando foram suprimidas essas questões nas minas escocesas".

Assim, levando em consideração que os patrões eram os proprietários das máquinas, começou a haver necessidade de intervenção estatal nas relações do trabalho. A hipossuficiência do trabalhador passa a ser considerada e o Estado intervém para realizar o bem-estar social e melhorar as condições de trabalho.

Neste sentido, Martins (2014) explica que a Inglaterra, em 1802, criou a Lei de Peel, por meio do qual pretendia dar amparo aos trabalhadores, ainda de forma autoritária, mas diminuindo a carga sobre-humana que era comum naquela época. Assim, a jornada foi limitada em 12 horas, de forma que o trabalho não poderia se iniciar antes das 6 horas e terminar após as 21 horas. Muitas conquistas foram alcançadas de forma gradual, como a proibição de trabalho de menores na França, que se deu em 1813, a vedação da realização deste aos domingos e feriados e a redução da jornada e crianças e adolescentes.

$\mathrm{Na}$ seara dos Direitos das mulheres, Jorge Neto e Cavalcante (2010) expõem que a Inglaterra, no ano de 1842, elaborou o Coal Mining
$A c t$, que proibia o trabalho de mulheres em subterrâneo. Logo após, o Factory Act em 1844 limitou o trabalho da mulher em 12 horas, restando proibido o período noturno. Por fim, em 1878, o Factory and Workshop $A_{c t^{3}}$ vedou a utilização de mulheres em trabalhos perigosos e insalubres.

Ainda de acordo com Jorge Neto e Cavalcante (2010), a França, por sua vez, em 1874, vetou o trabalho das mulheres em minas e pedreiras, além da proibição quanto ao trabalho noturno se fossem menores de 21 anos. Houve também, em 1892, a limitação da jornada das mulheres em 11 horas. Em 1900 foi imposto aos proprietários de estabelecimentos comerciais a obrigação de os aparelhar em cadeiras para as mulheres. $\mathrm{O}$ repouso não remunerado de 8 semanas para mulheres grávidas, com a proibição de carregar objetos pesados foi instituído em 1909 e a interdição do trabalho feminino nas partes exteriores das lojas em 1913.

Para Martins (2014), a legislação do trabalho é resultado da reação contra a exploração dos trabalhadores pelos empregadores e que o Direito do Trabalho surgiu para limitar os abusos do empregador em explorá-lo e para modificar condições do mesmo. Aos poucos, a legislação internacional passou a valorizar e proteger os trabalhadores.

Partindo desta premissa, Nascimento (2014, p. 45) enfoca que "a primeira Constituição do mundo que dispõe sobre direito do trabalho é a do México, de 1917’. Esta, previa jornada de

\footnotetext{
${ }^{1}$ Lei de Mineração do Carvão

${ }^{2}$ Lei da Fábrica

${ }^{3}$ Lei da Fábrica e Oficinas
} 
trabalho de oito horas; proibição de menores de 12 anos, limitação da jornada dos menores de 16 anos a seis horas; jornada máxima noturna de sete horas; descanso semanal; proteção à maternidade; salário-mínimo; direito de sindicalização e de greve; indenização de dispensa; seguro social e proteção contra acidentes de trabalho.

Martins (2014, p. 9) complementa expondo que a segunda Constituição a versar sobre o assunto foi a de Weimar (Alemanha), de 1919, que disciplinava a participação dos trabalhadores nas empresas, autorizando a liberdade de coalização dos trabalhadores, enfocando também sobre a representação dos trabalhadores na empresa e criou um sistema de seguros sociais e também a possibilidade de os trabalhadores colaborarem com os empregadores na fixação de salários e demais condições de trabalho.

A partir destas primeiras Constituições outros países passaram a tratar do Direito do Trabalho, constitucionalizando os direitos trabalhistas. Além disto, a OIT criou convenções e recomendações que versam sobre a proteção ao trabalho da mulher. Jorge Neto e Cavalcante (2010, p. 1095) elencam as convenções e recomendações de índole protecionista que foram estabelecidas.

Convenções: 3 (1919) - relativa ao trabalho da mulher antes e depois do parto;4 (1919) proibição do trabalho da mulher em oficinas públicas ou privadas, exceto se o trabalho for feito em oficinas de família; 41 (1934) - regula o trabalho noturno da mulher; 45 (1935) - vedação ao trabalho da mulher em subterrâneos e minas; 89 (1949) - a respeito do trabalho noturno das mulheres na indústria; 100 (1951) - disciplina a igualdade de remuneração entre homem e mulher para trabalho igual; 103 (1952) - relativa à proteção da maternidade; 111 (1956) - trata da discriminação em matéria de emprego e profissão; 127 (1967) - versa sobre o limite máximo de levantamento de pesos; 156 (1981) estabelece igualdade de oportunidades e de tratamento para trabalhadores dos 2 sexos em relação às responsabilidade familiares; 171 (1990) - a respeito do trabalho noturno, o qual compreende um período de 7 horas e realizado da 00:00 às 05:00 horas, tendo as mulheres proteção especial apenas em função da maternidade. Recomendações: 12 (1921) proteção antes e depois do parto; 13 (1921) - a respeito do trabalho noturno das mulheres na agricultura; 26 (1927) - versa quanto à proteção das mulheres emigrantes a bordo de embarcações; 67 (1944) - auxílio-maternidade; 90 (1951) - igualdade de remuneração entre homem e mulher; 92 (1952) - sobre a proteção da maternidade; 111 (1958) - a respeito das práticas discriminatórias no emprego ou ocupação; 165 (1981) - dispondo a respeito da igualdade de oportunidade e tratamento para os trabalhadores.

No que tange à regulamentação acerca do trabalho da mulher, além do que vem previsto pela OIT, existem legislações esparsas que versam sobre o referido tema, tais como os artigos $2^{\circ}$ e $7^{\circ}$ da Declaração Universal dos Direitos Humanos de 1948, o artigo $3^{\circ}$ do Pacto Internacional sobre Direitos Econômicos, Sociais e Culturais (Decreto n ${ }^{\circ} 591$, de 6 de julho de 1992) e o artigo 11.1 da Convenção da Organização das Nações Unidas sobre Eliminação de todas as Formas de Discriminação contra a Mulher (CEDAW, 1979; Decreto 4.377 de 13 de setembro de 2002).

$$
\text { Jorge Neto e Cavalcante }
$$

enumeram as áreas marcantes relativas ao sistema de proteção ao trabalho da mulher, sendo elas:

a) na duração da jornada de trabalho; b) na dos trabalhos noturnos; c) na dos trabalhos perigosos e insalubres; d) na do repouso semana; e) na da gravidez; f) na da maternidade; g) na da moralidade. Os principais fundamentos com base nos quais se procurou justificar o sistema 
em causa foram as seguintes: a) vocação da mulher para os serviços domésticos e a consequente necessidade de ser protegida, no interesse do marido e da família, contra a exploração abusiva dos empregadores; b) a debilidade da mulher, que a incapacita para trabalhos longos e penosos; c) o interesse social na prestação da saúde da mulher, dada a sua condição de produtora de seres humanos.

Neste ínterim, para Magano (1992) a concepção protecionista está em crise, uma vez que as normas protecionistas só se justificam em relação à gravidez e à maternidade, devendo assim, as demais serem abolidas, sobretudo quando engendrarem a possibilidade de discriminação. Trocando em miúdos, o autor conclui que hoje o entendimento dominante é no sentido de que, em lugar de normas protecionistas, o que realmente deve ser tutelado é o princípio da não discriminação.

Com reflexo dessa tendência da nãodiscriminação, em 1983, com a Lei 83.635, a França esclareceu a tendência moderna de resguardar os interesses das mulheres não através de normas protecionistas e sim mediante proibição de discriminações por motivo de sexo.

Sob a ótica da legislação brasileira, Martins (2014) verbera que, inicialmente, as Constituições brasileiras versavam apenas sobre a forma do Estado e o sistema de governo. A Constituição de 1824, por exemplo, tratou apenas de abolir as corporações de ofício, alegando que deveria haver liberdade do exercício de ofícios e profissões. A de 1891, por sua vez, previu a liberdade de associação que tinha na época caráter genérico, determinando que a todos era lícita a associação e reunião, livremente e sem armas, não podendo a polícia intervir, salvo para manter a ordem pública.

Martins (2014, p. 11) dispõe que "a Constituição de 1934 é a primeira constituição brasileira a tratar especificamente do Direito do Trabalho". Antes disto, contudo, Jorge Neto e Cavalcante (2010) rezam que o primeiro diploma legislativo foi o Decreto 21.417-A de 1932.

Calha a ressalva de que Jorge Neto e Cavalcante (2010) rechaçam ainda que a primeira Constituição a versar sobre a proteção ao trabalho da mulher foi a de 1934, que previa proibição da discriminação do trabalho da mulher em relação aos salários, vedação do trabalho da mulher em serviços insalubres, garantia do repouso semanal remunerado para a gestante e constituição dos serviços de amparo à maternidade.

Assim, além de ser a primeira Constituição brasileira a tratar de forma clara os direitos dos trabalhadores, a Constituição de 1934 trouxe as primeiras normas protecionistas ao trabalho da mulher, já com alguns traços de vedação à discriminação.

Com a criação da CLT em $1^{\circ}$ de maio de 1943, foi mantida a legislação protetora e o Decreto-Lei 6.353 de 1944 substituiu a proibição do trabalho noturno para a mulher, permitindo os serviços em alguma atividades, desde que houvesse a idade mínima de 18 anos.

$$
\text { Segundo Nascimento (2014), a }
$$

Constituição de 1967 previu as garantias já previstas nas normas anteriores, contudo, incluiu o direito da mulher à aposentadoria aos 30 anos de trabalho, com salário integral. 
Jorge Neto e Cavalcante (2010) complementam ainda que em 1967, com o Decreto-Lei 229, a CLT sofreu alterações passando a permitir o regime de compensação da jornada de trabalho mediante acordo coletivo, a possibilidade do trabalho noturno para mulheres maiores de 18 anos, desde que fosse em estabelecimento de ensinos, alteração quanto ao vestiário, maior rigor quanto ao empregador em relação ao local apropriado destinado à guarda de filhos de mulheres em período de amamentação e proibição do trabalho da mulher em período de 4 semanas antes e 8 semanas depois do parto.

Ao que diz respeito à Constituição Federal de 1988, Carta Magna vigente, pode-se destacar:

a) Art. $5^{\circ}, I$ - homens e mulheres são iguais em direitos e obrigações;

b) Art. $7^{\circ}, \mathrm{XXX}$ - proibição de diferença de salários, de exercício de funções e de critério de admissão por motivo de sexo;

c) Art. $7^{\circ}$, XVIII - licença à gestante, sem prejuízo do emprego e do salário, com a duração de 120 dias;

d) Art. 10, II, $b$ do ADCT - garantia de emprego à mulher gestante, desde a confirmação da gravidez até cinco meses após o parto;

e) Art. 201, III - seguro-maternidade;

f) Art. $7^{\circ}, \mathrm{XX}-$ proteção do mercado de trabalho da mulher, mediante incentivos.

Com a Lei 7.855 de 1989, que trouxe alterações a CLT, vários artigos deste diploma legal relacionados à proteção do trabalho da mulher foram revogados, adequando o certificado legal às novas necessidades do mercado de trabalho e a Lei 9.799 de 1999 incorporou à CLT os artigos 373-A, 390-B a 390-E e 392, \$4.

Com breve ressalva em âmbito internacional, a Convenção da ONU sobre Eliminação de todas as Formas de Discriminação contra a Mulher assevera que os Estados participantes adotarão todas as medidas apropriadas para eliminar a discriminação contra a mulher na esfera do emprego a fim de assegurar condições de igualdade entre homens e mulheres, conforme disposto anteriormente.

Atualmente, a CLT versa sobre a proteção do trabalho na mulher nos artigos 372 ao 401-B, sem prejuízos de outros artigos que proíbem discriminações de qualquer gênero, inclusive quanto ao sexo do trabalhador.

Em conformidade com o que afirma Jorge Neto e Cavalcante (2010, p. 1100), os fundamentos informados pela doutrina para justificar a intervenção do Direito na defesa da mulher trabalhadora são:

Fundamento fisiológico: a mulher não é dotada da mesma resistência física do homem e a sua constituição é mais frágil, de modo a exigir do direito uma atitude diferente e mais compatível com o seu estado;

Fundamento social: interessa à sociedade a defesa da família, daí porque o trabalho da mulher deve ser especialmente protegido de tal modo que a maternidade e as solicitações dela decorrentes sejam devidamente conciliadas com as ocupações profissionais.

Neste sentido, Nascimento (2014, p. 201) certifica que "em todos os sistemas jurídicos, 
a mulher merece tratamento particular, asseguradas condições mínimas de trabalho, diferentes e mais vantajosas daquelas estabelecidas em relação aos homens". Importante relembrar que nem sempre o pensamento foi nesta direção, pois no período da Revolução Industrial o trabalho feminino foi aproveitado em larga escala, sendo preferencial em relação ao trabalho masculino, por razão da menor remuneração.

De acordo com o artigo 377 da CLT, a adoção de medidas de proteção ao trabalho da mulher é matéria de ordem pública, não se justificando, em hipótese alguma, a redução do salário.

Convém salientar que, conforme Jorge Neto e Cavalcante (2010, p.1101), “o exacerbado protecionismo gerou uma discriminação do acesso da mulher ao mercado de trabalho". Com isso, houve a necessidade da restrição ao elevado número das medidas paternalistas, com a supressão das proibições ao trabalho noturno, trabalho em atividades insalubres e perigosas.

Neste contexto, Martins

dispõe que

as medidas paternalistas só se justificam em relação ao período de gravidez e após o parto, de amamentação e a certas situações peculiares à mulher, como de sua impossibilidade física de levantar pesos excessivos, que são condições inerentes à mulher. As demais formas de discriminação deveriam ser abolidas. (...) Verifica-se que os motivos de proteção ao trabalho da mulher são conservadores e, em vez de protegê-la, acabam discriminando-a. (Martins, 2007:593)

Assim, o que se busca não é a discriminação por meio de medidas paternalistas, mas sim a possibilidade de entrada das mulheres no mercado de trabalho de forma justa e igualitária.

\section{FLEXIBILIZAÇÃO DAS NORMAS TRABALHISTAS}

Assim como as próprias normas trabalhistas passaram por um processo de criação e aperfeiçoamento, a ideia de flexibilização foi algo aprimorado ao longo do tempo.

De acordo com Aguiar (2014), uma série de fatores desencadearam o conceito de flexibilização. A evolução tecnológica e a globalização são exemplos de fatores que tiveram como consequências graves a precarização e informalização das relações de emprego e o próprio desemprego. $\mathrm{O}$ fato da tecnologia substituir o lugar do homem através das máquinas, aumenta cada vez mais, a competitividade no mercado de trabalho, ocasionando, consequentemente, um índice maior de desemprego. A autora complementa ainda que

Surgida na Europa, durante a década de 60 do século XX, como um conjunto de ideias propagadas por pensadores e principalmente por operadores do Direito do Trabalho para fazer frente aos problemas como a excessiva rigidez das normas trabalhistas de países como a Itália, além daqueles decorrentes do avanço da tecnologia, do desemprego e da crise do petróleo de 1973, bem como das transformações políticas do leste europeu, em razão da necessidade de desenvolvimento das comunidades internacionais, a flexibilização foi concebida com o fim de reduzir o desemprego estrutural, modernizar as relações de trabalho e adequar o juslaboral às necessidades da empresa, aumentando a sua produtividade. O objetivo proposto pela flexibilização seria alcançado mediante a utilização de um conjunto de instrumentos jurídicos (normas, leis, acordos provenientes de negociações coletivas e etc.) que permitissem o ajustamento da produção, emprego e condições de trabalho às inovações tecnológicas, às permanentes flutuações da 
política e da economia, para tanto, o direito laboral teria que adotar um modelo jurídico mais próximo da vida das empresas para regular a relação de emprego, tendo em vista o aumento da produção, bem como da competitividade entre as empresas, ainda que para isso os direitos trabalhistas e o caráter protetivo juslaboral sejam mitigados. (AGUIAR, 2014, p. 2)

No mesmo sentido, Martins (2010, p. 26) ensina que "a flexibilização é decorrência do surgimento das novas tecnologias, da informática, da robotização, que mostram a passagem da era industrial para a pós-industrial, revelando uma expansão do setor terciário da economia".

Segundo Nassar (apud Soares e Massine, 2010, p. 4) “a flexibilização (...) não é univocamente definida". Assim, a palavra flexibilização é polissêmica, o que implica dizer que diversos significados podem the ser conferidos.

Desta feita, a partir da evolução da tecnologia, as relações de emprego passaram a receber uma atenção diferente, uma vez que a mão de obra humana passou a ser substituível, gerando então a necessidade de flexibilização de algumas normas a fim de manter o trabalhador nas empresas. O desemprego gerado pela própria tecnologia forçou o Direito a voltar os olhos para esta situação e encontrar um meio para proteger o trabalhador nos momentos em que a empresa estiver passando por crise econômica.

Por esta razão Cassar (2015, p. 5) verbera que em relação ao "confronto travado entre a necessidade de se manter um Estado social de direito e a crise econômica das empresas, a flexibilização se mostra como o melhor meio de composição deste conflito, mas de forma responsável e sem abuso".
É notório ressaltar as palavras de Aguiar (2014, p. 02) que dispõe que,

\begin{abstract}
Além da globalização e do avanço tecnológico, outro problema enfrentado pelo Direito do Trabalho, está no caráter rígido de sua legislação, apontada pela classe empresarial e por empregadores em geral como uma das grandes causadoras da crise do desemprego, com o pretexto de que o excessivo intervencionismo estatal, excesso dos encargos decorrentes da formalização do contrato e a morosidade da justiça estariam fazendo com que os empregadores empregassem menos e desempregassem mais. Diante da necessidade da reformulação da legislação trabalhista, uma das propostas que se apresenta como solução à crise do desemprego, bem como à necessidade de regulamentação das novas relações de trabalho, entre outros problemas surgidos em decorrência do processo de globalização, do avanço tecnológico e da economia de mercado é a flexibilização das normas laborais.
\end{abstract}

Domingues (2011, p. 34), discorre ainda que "no contexto atual da globalização, o objetivo da flexibilização é evitar a extinção de empresas e consequentemente reduzir a taxa de desemprego, garantindo direitos mínimos aos trabalhadores". Reitera-se, portanto, o intuito de preservar a empresa e os empregados nos possíveis momentos de crise. Infere-se, portanto, que a necessidade de flexibilização das normas trabalhistas se dará nos períodos de crise como em decorrência do progresso tecnológico (MACHADO, 2008).

Exemplificando o instituto da flexibilização, Delgado (2014, p. 609) discorre que

A Lei $n^{\circ}$ 9.601/98, entretanto, parece querer firmar marco distinto e mais extremado do processo flexibilizatório trabalhista no país. Pelo texto deste diploma, a linha flexibilizatória deixa de preponderar pela simples e adequação do caráter genérico das leis trabalhistas às circunstâncias e especificidades de segmentos do mercado de trabalho e setores produtivos e 
profissionais, através da negociação coletiva. [...] Passa-se a perceber na norma jurídica heterônoma estatal e na negociação coletiva instrumentos de pura e simples redução de direitos.

Assim, Cassar (2009) conclui que a flexibilização deve ser um mecanismo utilizado apenas quando os reais interesses entre empregado e empregador forem convergentes, de forma a evitar o uso indevido deste instituto $\mathrm{e}$ evitando um conceito eivado de vícios. Cassar (2015, p. 3) leciona ainda que "a garantia de direitos mínimos ao trabalhador faz parte de um conjunto de valores humanos civilizatórios, que encontra respaldo no princípio da dignidade da pessoa humana previsto constitucionalmente como maior patrimônio da humanidade".

Além disto, há de se lembrar de um dos princípios mais importantes na seara do Direito do Trabalho, que é o Princípio da Proteção, visa resguardar os direitos dos trabalhadores, tendo em vista sua situação de vulnerabilidade frente ao empregador. Referido princípio é conceituado por Delgado (2014, p. 196) como um

princípio que o Direito do trabalho "estrutura em seu interior, com suas regras, institutos, princípios e presunções próprias, uma teia de proteção à parte hipossuficiente na relação empregatícia, visando atenuar, no plano jurídico, o desequilíbrio ao plano fático do contrato de trabalho.
Com base nestes princípios, rechaçase, portanto, o caráter excepcional da flexibilização, respeitando-se os direitos dos trabalhadores, no afã de evitar abusos e redução de garantias conquistadas ao longo do tempo.

A flexibilização pode ser considerada "sob a forma da adaptação, que é uma versão mais branda, e sob a forma da desregulamentação, considerada uma forma mais abrupta" (AGUIAR, 2014, p. 02). Contudo, não existe unanimidade na doutrina acerca das modalidades.

De forma mais ampla, Cassar (2010) esclarece que há inúmeras formas de classificar as flexibilizações, considerando dentre elas a de adaptação, a autônoma ou heterônoma, de proteção e a por desregulamentação as com maior relevância. Assim, conveniente ressaltar o que a Pedrosa e Almeida (2014, online) lecionam acerca dessas qualificações elencadas na obra de Cassar (2010),

Há inúmeras formas de classificar as flexibilizações, Vólia Cassar traz algumas espécies como a flexibilização de adaptação que visa a fazer adaptações por intermédio de autonomia coletiva, não se limitando a tirar benefícios trabalhistas previstos em normas nacionais. Outra espécie de flexibilização é a de proteção que só permite a alteração da norma trabalhista para favorecer o operário, não sendo possível a utilização da flexibilização para retirar direitos mínimos dos trabalhadores, mas caso o haja riscos ao empreendimento pode haver a prevalência do interesse do empregador sobre o interesse do empregado. A flexibilização por desregulamentação substitui uma legislação rígida por um menos favorável a empregado, como entre a revogação e a substituição há um vazio legislativo, essa ocasião dar-se espaço à negociação entre as partes [...]. Há também a flexibilização autônoma em que há a utilização de acordo e convenções coletivas, ou seja, há uma autonomia dos empregados e empregadores para acordarem seus direitos e obrigações. Em 
contrapartida há também a flexibilização heterônoma onde o Estado é detentor das feituras das leis e decretos, podendo este autorizar a derrogação ou substituição das normas, podendo ser feita de forma unilateral pelo empregador.

Domingues (2011, apud CREPALDI, 2003, p. 68), por sua vez, ensina que a flexibilização pode ocorrer "modernizando a legislação, suprindo ou acrescentando-lhes dispositivos, oferecendo alternativas para a solução dos problemas existentes e incentivando a negociação".

Martins (2010, p. 526) discorre como essência da flexibilização, que

Visa assegurar um conjunto de regras mínimas ao trabalhador, e em contrapartida, a sobrevivência da empresa, por meio da modificação de comandos legais, procurando garantir aos trabalhadores certos direitos mínimos e ao empregador a possibilidade de adaptação de seu negócio, mormente em épocas de crise econômica.

Acerca da intervenção estatal nas relações trabalhistas e sobre seus riscos, Machado (2008, p. 55) adverte que

O grande conflito em torno da Flexibilização é que de um lado, tem-se o entendimento de que o Estado tem que continuar intervindo nas relações de trabalho, visando a preservar o trabalhador dos abusos do empregador. Do outro, há os que defendem que a flexibilização é fundamental para a sobrevivência do Direito do Trabalho, haja vista dar maior mobilidade para a empresa regular as condições de trabalho, e com isso, garantindo o emprego dos trabalhadores e a sobrevivência da própria empresa em tempos de crise. [...] A Flexibilização representa a atenuação da rigidez protetiva do Direito do Trabalho, com a adoção de condições trabalhistas menos favoráveis do que as previstas em lei, mediante negociação coletiva, em que a perda de vantagens econômicas poderá ser compensado pela instituição de outros benefícios, de cunho social, que não onerarão excessivamente a empresa, nos períodos de crise ou de transformação na realidade produtiva.

Desta feita, Süssekind (apud Perez, 2014, p. 07) enfoca a flexibilização e a desregulamentação, levando em consideração que esta pode ser considerada uma espécie daquela, tratando de forma mais específica a maneira de flexibilizar as normas, sendo que

a flexibilização tem por objetivo: a) o atendimento a peculiaridades regionais, empresariais ou profissionais; b) a implementação de nova tecnologia ou de novos métodos de trabalho; c) a preservação da saúde econômica da empresa e o emprego dos respectivos empregados. Já a desregulamentação retira a proteção do Estado ao trabalhador, permitindo que a autonomia privada, individual ou coletiva, regule as condições do trabalho e os direitos e obrigações advindos da relação de emprego.

Por esta razão Lopes (2014, online) afirma que desregulamentação significa "retirar as normas heterônomas das relações de trabalho, de tal forma que a vontade dos sujeitos é que estabelecerá as normas que devem comandar as suas relações, [...] é a extinção gradual de regras imperativas, com a ampliação da liberdade de convenção".

Salutar a ressalva de que a desregulamentação classifica-se como uma forma de flexibilização quanto a sua finalidade, suprimindo direitos trabalhistas. Um exemplo desta espécie é a Lei do FGTS (Lei n 5.107/66 e 8.036/90) que trocou a estabilidade do trabalhador no emprego pela constituição de um 
fundo e pagamento de verba indenizatória (MACHADO, 2008).

Com base nesta informação, compreende-se que embora exista a figura da desregulamentação, a mesma não é aplicada no ordenamento jurídico brasileiro de forma ampla. Procura-se então, uma solução em casos de necessidade imperiosa e não a ausência do Estado na regulamentação das relações de trabalho, uma vez que, como bem explica Domingues (2011), o escopo da desregulamentação é o retorno ao regime da livre contratualidade, onde o Estado realizava o papel de mero espectador dos conflitos entre capital e trabalho.

Assim, de acordo com Carvalho (2000, online)

não há que se confundir flexibilização e desregulamentação, sendo esta última caracterizada pela total ausência do Estado no disciplinamento das relações de trabalho, permitindo assim um maior desenvolvimento da plena liberdade sindical e das normatizações coletivas no âmbito privado das relações entre capital e trabalho.[...]desregulamentação é vocábulo que deve ser restrito ao direito coletivo do trabalho, não se aplicando ao direito individual do trabalho para o qual existe a palavra flexibilização. Assim, desregulamenta-se o coletivo e flexibiliza-se o individual. Portanto, desregulamentação seria a política legislativa de redução da interferência da lei nas relações coletivas de trabalho, para que se desenvolvam segundo o princípio da liberdade sindical e das representações de trabalhadores.

Embora a doutrina ainda não esteja em consenso, a maioria ainda defende a figura da flexibilização por adaptação em detrimento da desregulamentação. Isto porque, como será mais explanado mais a frente, a Constituição Federal de 1988 trouxe um forma taxativo de possibilidade de flexibilização das normas trabalhistas frente às necessidades imperiosas do empregador.

Como bem explica Soares e Massine (2010, p.7), a Carta Constitucional, através da adaptação de suas cláusulas, procura "atender às exigências tecnológicas, econômicas, sociais e comerciais modernas, sempre buscando oferecer ao trabalhador segurança jurídica quanto à flexibilização das normas trabalhistas", de forma que seja cumprida com o objetivo maior de "conservar e zelar pela dignidade da pessoa humana, principal fundamento do Estado Democrático de Direito".

\section{A FLEXIBILIZAÇÃO $\mathrm{E}$ A CONSTITUIÇÃO FEDERAL DE 1988}

De acordo com Nascimento (2013) ensina que a flexibilização não prejudica a função protetora inerente ao Direito do Trabalho, tendo em vista que os direitos da personalidade, por exemplo, não são afetados por esta nova tendência. Isto porque esta proteção ao trabalhador está garantida no texto constitucional através do princípio da dignidade humana, que se sobrepõe ao plano contratual, juntamente por razão do cunho protecionista do Direito do Trabalho.

Por esta razão, Gonçalves (2011, p. 8) leciona que "a flexibilização possui o intuito de adaptar a legislação trabalhista a uma perspectiva global". Assim, a intenção não deve ser de supressão de direitos, mas sim de adaptação dos mesmos ao contexto geral. 
A possibilidade de flexibilizar deve ser vista e tratada com limites. Domingues (2011, p. 47) ressalta que

\begin{abstract}
Alguns doutrinadores classificam os limites da flexibilização quanto à admissibilidade e quanto à proibição. Quanto à admissibilidade, subdividese em dois tipos: a) admissíveis: são aqueles utilizados apenas em ocasiões especiais, como por exemplo em épocas de crise, permitindo a continuidade da empresa, mas garantindo um mínimo ao trabalhador. Geralmente é realizado por meio de negociação coletiva; b) inadmissíveis: são aqueles criados apenas para reduzir direitos trabalhistas. Quanto à proteção, distingue-se em: a) proibida: aquela onde a própria lei pró́be a flexibilização; b) autorizada ou permitida: quando a lei autoriza a flexibilização, como por exemplo, o artigo $7^{\circ}$, VI da CF que permite a redução dos salários mediante convenção ou acordo coletivo.
\end{abstract}

A partir deste entendimento, o art. 468 da CLT prevê uma limitação clara às alterações no contrato de trabalho, tendo em vista a situação hipossuficiente do trabalhador frente ao empregador.

Art. 468 - Nos contratos individuais de trabalho só é lícita a alteração das respectivas condições por mútuo consentimento, e ainda assim desde que não resultem, direta ou indiretamente, prejuízos ao empregado, sob pena de nulidade da cláusula infringente desta garantia.

\section{A legislação protecionista brasileira} visa impedir a flexibilização de forma demasiada e em prejuízo ao trabalhador. Por esta razão, a Constituição Federal de 1988 é clara nas possibilidades de flexibilização na seara trabalhista brasileira.

Machado (2008, p. 70) norteia que o sistema constitucional brasileiro é "caracterizado pelo predomínio do legislado sobre o convencionado entre as partes, ou seja, pelo dirigismo do Estado nas relações do trabalho e na menor amplitude da autonomia da vontade e das negociações coletivas em relação".

Contemporaneamente,

flexibilização é permitida quando tiver ligação com os seguintes dispositivos constitucionais:

CF/88, Art. $\mathbf{7}^{\mathbf{o}}$ - São direitos dos trabalhadores urbanos e rurais, além de outros que visem à melhoria de sua condição social:

VI - irredutibilidade do salário, salvo o disposto em convenção ou acordo coletivo;

XIII - duração do trabalho normal não superior a oito horas diárias e quarenta e quatro semanais, facultada a compensação de horários e a redução da jornada, mediante acordo ou convenção coletiva de trabalho;

XIV - jornada de seis horas para o trabalho realizado em turnos ininterruptos de revezamento, salvo negociação coletiva;

Para Lopes (2000), SubprocuradorGeral do Trabalho na época, em suas ponderações doutrina que a flexibilização somente poderá se exteriorizar por intermédio da negociação coletiva, que tem como vetores o acordo e a convenção coletiva.

Como regra geral, as condições mínimas de trabalho previstas na CF são inderrogáveis pela vontade das partes, mesmo na esfera da autonomia privada coletiva. A Constituição abriu uma exceção ao permitir a flexibilização das condições de trabalho no art. 7o, incisos VI, XIII e XIV. Na primeira hipótese, o constituinte aludiu a convenção e acordo coletivo; na segunda, a acordo ou convenção coletiva; e na terceira, a negociação coletiva, entretanto, como a convenção e o acordo coletivo são os instrumentos da negociação coletiva, pode-se afirmar, como regra geral, que a flexibilização decorre da negociação coletiva e se exterioriza (ganha contornos jurídicos ou se instrumentaliza) em acordos ou convenção coletiva de trabalho. Com a flexibilização o constituinte teve por escopo a tutela do emprego, já que a rigidez do sistema legal vigente antes de 1988 não permitia, salvo hipóteses restritíssimas, qualquer redução dos direitos trabalhistas na vigência do contrato de trabalho, ainda que pela via da negociação coletiva. Tal rigidez, somada à crise econômica, às oscilações comuns ao mercado e à 
globalização da economia, resultava na impossibilidade jurídica de redução da folha de pagamento e transposição da crise sem o fechamento de empresas e a redução de postos de trabalho, ou ainda, no simples descumprimento das normas trabalhistas pelo empresário em dificuldades financeiras, que simplesmente as olvidava para demitir seus empregados sem qualquer pagamento indenizatório, deixando a questão se arrastar anos a fio nos tribunais do trabalho.

Entretanto, há quem não concorde com a possibilidade expressa da Constituição Federal de 1988 em permitir a flexibilização em algumas situações específica. Martins (2010, p. 70) afirma que "a clássica descrição dos subprincípios do princípio da proteção (in dúbio pro operario, norma mais favorável e condição mais benéfica) não condiz com a realidade normativa constitucional". A autora entende que as três hipóteses constitucionais de flexibilização permitem expressamente alterações contratuais in pejus por meio da via negocial. Esta, contudo, não é a opinião majoritária.

Machado (2010, p. 72) ressalta que em regra, "tanto no plano do direito individual do trabalho, quanto no coletivo, as alterações in mellius são sempre permitidas. Já as alterações in pejus são permitidas no plano coletivo, somente. Ao passo que, no plano individual, são vedadas". Este, pondera ainda que,

[...] tão-somente os incisos VI e XIV do art. $7^{\circ}$ da Carta Constitucional

caracterizaria flexibilização in pejus; ao passo que, o inciso XIII, do referido artigo, que trata da jornada parcial, seria Flexibilização in mellius. Tal afirmação se faz, uma vez que se presume um piso salarial maior ou igual ao mínimo, onde o trabalhador prestaria serviços numa jornada de tempo menor. Portanto, somente quando combinado com o inciso VI do art. $7^{\circ} \mathrm{da}$ Constituição, é que se tornaria flexibilização in pejus (como, por exemplo, a redução da jornada de trabalho junto com o salário). Uma vez que o inciso XIII, art. $7^{\circ}$ da Constituição apregoa a possibilidade de jornada parcial de 25 horas semanais. Beneficiando, destarte, não só o empregado contratado por este regime, como também uma coletividade e, consequentemente, a economia do país (mais pessoas trabalhando, mais bens sendo consumidos). (MACHADO, 2010, p. 73)

Contudo, cumpre rechaçar que o intuito da flexibilização não é permitir abusos contra os trabalhadores, mas sim o de prolongar o contrato de trabalho mesmo em tempos de crise. Isto porque, o afastamento da rigidez de algumas leis fez-se necessária para a adaptação de novas tendências, como disposto anteriormente.

Perez (2007, p. 9-10) afirma que

No plano constitucional, apenas esses três
direitos podem ser flexibilizados, cabendo às
partes determinar as normas que passarão a reger
suas relações de acordo com seus interesses,
mediante acordo ou convenção coletiva de
trabalho. No plano infraconstitucional, as
flexibilizações apresentadas foram impostas pelo
Estado, como por exemplo: a criação do FGTS,
a Súmula $\mathrm{N}^{\circ} 331$ do Tribunal Superior do
Trabalho que dispõe sobre a terceirização, mais
recentemente a Lei $9.601 / 98$, algumas medidas
provisórias que instituíram o trabalho a tempo
parcial e a suspensão contratual para qualificação
profissional.

É possível entender a partir desta colocação que a base constitucional para a flexibilização é resumida nos três incisos supracitados do art. $7^{\circ}$ da Carta Magna. Resende e Zapata (2014) aduzem que “as hipóteses elencadas constituem-se num rol exaustivo, não havendo possibilidade de serem estendidas." Desta forma, "se o legislador se atentou tão somente para os três casos expressamente previstos, a intenção da lei não é estender a ampla flexibilidade aos demais direitos". 
É notório ressaltar que o texto constitucional permite a flexibilização por intermédio da negociação coletiva. Para Marques (2013, p. 198) ela "funda-se na teoria da autonomia privada coletiva e tem por objetivo suprir a insuficiência do contrato individual do trabalho". Desse modo, o processo da negociação é mais simples se comparado com o da elaboração $\mathrm{da}$ lei e atende às peculiaridades das partes envolvidas.

A partir desta concepção, Delgado (2014) aduz que a importância da negociação coletiva transcende o próprio Direito do Trabalho. Acrescenta ainda que a negociação coletiva enquadra-se no grupo das fórmulas autocompositivas dos métodos de solução de conflitos. Sendo assim, é considerada uma forma autocompositiva essencialmente democrática, que gera interesses profissionais e econômicos de significativa relevância social.

Ainda sobre a essência da negociação coletiva, Nascimento (2014, p. 504-505) acrescenta as funções política, econômica e social deste instituto, sendo elas

A negociação coletiva cumpre uma função política enquanto forma de diálogo entre grupos sociais numa sociedade democrática, cuja estrutura política valoriza a ação dos interlocutores sociais, confiando-lhes poderes para que, no interesse geral, superem as suas divergências. [...] Cumpre uma função econômica de meio de distribuição de riquezas numa economia em prosperidade, ou, também, uma função ordenadora numa economia em crise. A negociação coletiva é um instrumento do processo econômico e, como tal, deve ser compreendida. [...] Cumpre ainda uma função social de garantia de participação dos trabalhadores no processo de decisão empresarial, em proveito da normalidade das relações coletivas e de harmonia no ambiente de trabalho, dela se valendo inclusive a lei, que transfere para a negociação coletiva a solução de inúmeras questões de interesse social.

Dito isso, faz-se importante a breve conceituação dos elementos que materializam a negociação coletiva, qual seja, o acordo coletivo de trabalho e a convenção coletivas de trabalho (ACT e CCT).

Marques (2013) prevê que tanto o acordo como a convenção coletiva decorrem da negociação coletiva, sendo que existe diferenças quanto à legitimação desses instrumentos normativo. Dessa forma, Delgado (2014) leciona que a convenção coletiva é pactuada entre sindicatos e o acordo coletivo é realizado pelo sindicato profissional e a empresa ou empresas.

Destarte, Marques (2013, p. 200) verbera que

\begin{abstract}
A negociação coletiva ocorre em dois níveis, o de categoria e o de empresa. Assim, as convenções coletivas de trabalho resultam das negociações decorrentes de categoria e se aplicam a todos os empregados e empregadores, sócios ou não dos sindicatos, do setor de atividade em que a negociação se desenvolver. Com relação à negociação de empresa, do resultado satisfatório surgem os acordos coletivos, cujo âmbito de aplicação é menor, pois participam da negociação uma ou mais empresas e não toda a categoria.
\end{abstract}

Atualmente a legislação brasileira não permite flexibilização de temas que fujam do que está previsto no art. $7^{\circ}$ da Constituição Federal de 1988. Portanto, somente podem ser flexibilizadas normas que versem sobre salário e jornada de trabalho, por meio de negociação coletiva.

Logo, não existem distinções referentes ao ofício realizado pelo homem ou pela mulher após a Constituição Federal de 1988. Dessa forma, Salgado (2009) expõe que embora a 
CLT tenha previsto diversos artigos ao trabalho da mulher,

grande parte desses dispositivos foram suprimidos, devido à incompatibilidade com o art. $5^{\circ}$ da Constituição Federal, que prega a igualdade entre homens e mulheres". Essa igualdade só tem algumas exceções quando se trata de proteger a mulher na devido a sua constituição física, e principalmente para proteger a mulher enquanto mãe.

Como disposto anteriormente, "a mulher foi introduzida no âmbito do trabalho no capitalismo moderno, em substituição à mão de obra masculina, mais cara e em alguns momentos escassa" (SALGADO, 2009). Ela sempre foi uma das grandes vítimas da diminuição dos direitos trabalhistas, e a flexibilização destes recai sobre esse sujeito de direito. Essa flexibilização se dá nas jornadas parciais de trabalho, em que há tempo de trabalho reduzido e com isso um salário também reduzido.

Frente ao instituto da flexibilização, os direitos trabalhistas da mulher são postos acima de alterações que possam suprimir suas garantias. A jurisprudência atual segue o entendimento de que, as garantias e direitos versam sobre questões da saúde da mulher.

No que tange aos direitos referentes às mulheres, o entendimento da jurisprudência também é no sentido de vedação das práticas discriminatórias. Como visto, durante a Revolução Industrial a mulher teve seu trabalho explorado e menosprezado, quando era obrigada a trabalhar mais e receber menos que os homens. Contudo, atualmente a Constituição Federal de 1988 resguarda as mulheres de qualquer tipo de prática discriminatória.
RECURSO DE REVISTA. TROCA DE UNIFORME. TEMPO À DISPOSIÇÃO DO EMPREGADOR. FLEXIBILIZAÇÃ̃ POR NORMA COLETIVA. IMPOSSIBILIDADE.

Decisão do TRT contrária à OJ no 372 da SBDI1 do TST: "A partir da vigência da Lei $\mathrm{n}^{\circ} 10.243$, de 19.06.2001, que acrescentou o $\int 1^{\circ}$ ao art. 58 da CLT, não mais prevalece cláusula prevista em convenção ou acordo coletivo que elastece o limite de 5 minutos que antecedem e sucedem a jornada de trabalho para fins de apuração das horas extras". Recurso de revista de que se conhece e a que se dá provimento. PROTEÇÃO DO TRABALHO DA MULHER. INTERVALO ANTERIOR À PRORROGAÇÃO DA JORNADA. ART. 384 DA CLT. RECEPÇÃO PELA CONSTITUIÇÃO FEDERAL. Na atual jurisprudência do TST é considerado que o art. 384 da CLT foi recepcionado pela Constituição Federal de 1988. Não se trata aqui de discutir a igualdade de direitos e obrigações entre homens e mulheres. A mulher não é diferente como força de trabalho, pode desenvolver com habilidade e competência as atividades a que se dispuser ou que lhe sejam impostas. No entanto, o legislador procurou ampará-la, concedendo-lhe algumas prerrogativas voltadas para a proteção da sua fisiologia. Recurso de revista a que se dá provimento. (TST - RR: $10055620115120020 \quad 1005$ 56.2011.5.12.0020, Relator: Kátia Magalhães Arruda, Data de Julgamento: 06/02/2013, 6 ${ }^{\mathrm{a}}$ Turma, Data de Publicação: DEJT 15/02/2013)

A jurisprudência é clara ao reforçar a proibição de normas coletivas que tendem a suprimir direitos não permitidos a serem flexibilizados, como aqueles que foram instituídos no afã de proteger a fisiologia da mulher trabalhadora.

RECURSO DE REVISTA. PROCESSO ELETRÔNICO - MINUTOS QUE ANTECEDEM E SUCEDEM A JORNADA DE TRABALHO. NORMA COLETIVA. FLEXIBILIZAÇÃO. IMPOSSIBILIDADE. Esta Corte não tem reconhecido validade aos instrumentos normativos que elastecem o limite de 5 minutos que antecedem ou sucedem a jornada de trabalho para fins de apuração de horas extras, conforme $\mathrm{O}$ entendimento preconizado na OJ 372 da SBDI-1 do TST. Recurso de Revista conhecido e provido. [...] 
INTERVALO. DESCANSO ANTERIOR À JORNADA EXTRAORDINÁRIA. NORMA DE PROTEÇÃO À MULHER. O descumprimento do intervalo previsto no artigo 384 da CLT não importa mera penalidade administrativa, mas enseja o pagamento de horas extras correspondentes àquele período, tendo em vista tratar-se de medida de higiene, saúde e segurança da trabalhadora. Precedentes. Recurso de Revista conhecido e provido. (TST - RR: 12112620105120046 , Relator: Márcio Eurico Vitral Amaro, Data de Julgamento: 18/06/2014, $8^{\text {a }}$ Turma, Data de Publicação: DEJT 24/06/2014)

Logo, entende-se que direitos que versem sobre a saúde da mulher, como o intervalo de quinze minutos antes do período extraordinário, não podem ser suprimidos nem flexibilizados, em razão de seu cunho protetivo. $\mathrm{O}$ Tribunal Superior do Trabalho entende que não existem distinções entre homens e mulheres com relação aos direitos e obrigações, mas que a mulher merece um tratamento diferenciado em decorrência do desgaste físico ser maior ao desempenhar determinadas funções.

AGRAVO DE INSTRUMENTO EM RECURSO DE REVISTA. 1. INTERVALO PREVISTO NO ART. 384 DA CLT. PROTEÇÃO AO TRABALHO DA MULHER. Nos termos da jurisprudência desta Corte Superior, a disposição contida no art. 384 da CLT foi recepcionada pela Constituição Federal. Assim, homens e mulheres, embora iguais em direitos e obrigações, diferenciam-se em alguns pontos, especialmente no que concerne ao aspecto fisiológico, merecendo, portanto, a mulher um tratamento diferenciado quando o trabalho lhe exige um desgaste físico maior, como nas ocasiões em que presta horas extras. Por essa razão, faz jus ao intervalo de quinze minutos antes do início do período extraordinário. Precedentes. [..] (TST - AIRR: 21413720125180101 2141-37.2012.5.18.0101, Relator: Dora Maria da Costa, Data de Julgamento: 23/10/2013, $8^{\text {a }}$ Turma, Data de Publicação: DEJT 25/10/2013)

Denota-se, a partir da leitura da jurisprudência vigente, que os direitos das mulheres são tratados de forma especial, uma vez que abordam temas que dizem respeito ao aspecto fisiológico e papel social que ocupa no meio familiar, como mãe e dona de casa, impondo-lhe dupla jornada.

Desta feita, não podem ser objeto de flexibilização nenhum dos direitos trabalhistas das mulheres que não sejam abrangidos pelas possibilidades constitucionais dispostas anteriormente ou que tratem da saúde da mulher. Por fim, Salgado (2009) expõe que "quaisquer dispositivos que possam discriminar a mulher não possibilitando sua equiparação ao homem como trabalhador, excetuando casos de proteção a sua constituição física e a maternidade, são discriminatórios e não devem ser utilizados".

Isto porque, o intuito precípuo da legislação trabalhista brasileira deve ser da valorização da mulher e respeito à sua condição, sem estabelecer discriminação pelo sexo, mas estipulando a inserção no mercado de trabalho com respeito às diferenças do corpo feminino em relação ao masculino.

\section{CONSIDERAÇÕES}

Em suma, por meio das pesquisas e estudos realizados, o instituto da flexibilização surge como consequência da evolução tecnológica e da globalização. Dessa forma, sua utilização no campo do Direito do Trabalho também é considerada como consequência das altas taxas de desemprego causadas pela evolução da tecnologia em substituição da mão de obra humana.

As consequências da crise econômica no âmbito trabalhista forçaram a estipulação da 
flexibilização em determinadas situações constitucionalmente definidas, com o intuito de salvaguardar os direitos tanto dos empregados como dos empregadores.

O escopo da presente pesquisa foi o de analisar os limites da flexibilização frente os direitos trabalhistas das mulheres. Embora a Constituição Federal de 1988 tenha estipulado a igualdade entre homens e mulheres, a CLT e algumas leis específicas versam sobre direitos inerentes às mulheres, no afã de garantir proteção em determinadas situações.

Sendo assim, restou subentendido que as possibilidades constitucionais de flexibilização no Brasil são as que abordam sobre redução salarial ou jornada de trabalho. O próprio artigo $7^{\circ}$ elenca estas possibilidades, devendo, portanto, o legislador e as negociações coletivas ficar adstritas às mesmas.

Os direitos garantidos às mulheres que dizem respeito à saúde e maternidade não podem ser objeto de flexibilização, justamente pela natureza de suas normas. O princípio da proteção, uma das bases o Direito do Trabalho, resguarda a trabalhadora enquanto exerce sua função como empregada, mas respeita a condição de fragilidade em circunstâncias onde se faça necessário maior cuidado.

O intuito da flexibilização é evitar abusos contra a classe trabalhadora, com o esforço de manter o contrato de trabalho mesmo em tempos de crises, não faz sentido suprimir direitos das mulheres, que lutaram durante muito tempo para serem reconhecidas e respeitadas no mercado de trabalho.
Convém salientar que para haver flexibilização, é necessária a negociação coletiva para exteriorizar as mudanças temporárias para cada situação em concreto. Assim, o empregador não pode utilizar deliberadamente de seu poder de comando para decidir o que irá ou não flexibilizar. A participação do sindicato garante ao empregado que seus direitos sejam defendidos em nome do coletivo, evitando abusos e decisões tendenciosas a apenas determinadas classes.

Partindo em busca por respostas para as problemáticas estabelecidas, conclui-se que, embora ainda exista discriminação, abusos e assédio com relação às mulheres trabalhadoras, a legislação vem respeitando e resguardando os direitos que estão ligados à natureza da mulher, envolvendo a fragilidade física e a maternidade. $\mathrm{O}$ art. 389 da CLT, supracitado no presente trabalho, rechaça a importância dada às necessidades das mulheres, buscando evitar o esgotamento físico das mesmas no horário de trabalho. Muito além de novas legislações, é necessário fiscalização para garantir a efetividade de tais normas.

$$
\text { Em resumo, os princípios }
$$
constitucionais protecionistas exercem função importantíssima com o intuito de evitar abusos contra os trabalhadores, de forma que nenhum empregador ou seu sindicato possa se valer da flexibilização para suprimir direitos. Resta incontroverso que a luta do Direito do Trabalho deve ser contra a utilização equivocada da flexibilização, não contra o instituto em si. A busca pela continuidade da relação empregatícia poderá permitir redução de direitos em tempos de 
crises, desde que seja mantido o vínculo entre empregado e empregador.

Por fim, conclui-se que os direitos trabalhistas das mulheres passaram e continuarão passando por mudanças e adequações significativas aos diversos cenários econômicos vindouros, contudo, o importante é não esquecer que, independente do gênero sexual, nenhum trabalhador deverá ser prejudicado, nem ter direitos suprimidos sem a devida necessidade $\mathrm{e}$ sem a representação do sindicato de classe em defesa dos seus associados. Não obstante, todas transformações e conquistas até o presente momento, são de grande valia, tendo em vista que as diferenças devem ser respeitadas, sem distinções ou preconceitos.

\section{REFERÊNCIAS BIBLIOGRÁFICAS}

AGUIAR, Maria Herika Ivo. Flexibilização das leis trabalhistas. Alternativa à crise de desemprego? Jus Navigandi, Teresina, ano 19, n. 4182, 13 dez. 2014. Disponível em: . Acesso em: 19 mar. 2015.

ALMEIDA, Larissa Silva; PEDROSA, Eva Danielle. Proibição do retrocesso social e a condição mais favorável como princípios limitadores da flexigurança. Webartigos, Maranhão, nov. 2014. Disponível em:

http://www.webartigos.com/artigos/proibicao-doretrocesso-social-e-a-condicao-mais-favoravel-comoprincipios-limitadores-da-flexiguranca/126646/. Acesso em: 20 abr 2015.

BRASIL. Constituição da República Federativa do Brasil de 1988. Brasília, DF. Disponível em: . Acesso em 04 mai. 2015

\section{. Decreto-Lei n. ${ }^{\circ} 5.452$, de $1^{\circ}$ de maio}

de 1943 - Consolidação das Leis do Trabalho. Brasília, DF. Disponível em: . Acesso em 04 mai. 2015.

CARRION, Valentim. Comentários à

Consolidação das Leis do Trabalho. 36. ed. atual. Por Eduardo Carrion. São Paulo: Saraiva, 2011.
CARVALHO, Luiz Henrique Sousa de. A flexibilização das relações de trabalho no Brasil em um cenário de globalização econômica. Revista Jus Navigandi, Teresina, ano 5, n. 48, 1 dez. 2000. Disponível em: http://jus.com.br/artigos/1147. Acesso em: 11 maio 2015.

CASSAR, Vólia Bomfim. Direito do Trabalho. 2. ed. São Paulo: Impetus, 2008.

CASSAR, Vólia Bomfim. Atualidades em Direito do Trabalho. Valinhos: Anhanguera Educacional, 2015.

DELGADO, Mauricio Godinho. Curso de direito do trabalho. 13. Ed. São Paulo: LTr, 2014.

DOMINGUES, Suelen Martins. A flexibilização das normas trabalhistas. Monografia (Graduação) Faculdade Cenecista de Varginha, MG, 2011

GONÇALVES, Heloísa Alva Cortez.

Flexibilização das normas trabalhistas e a integridade física do trabalhador como aspecto fundamental da personalidade. Revista de Direito Público, Londrina, v. 6, no 1, p. 91-110, jan/abr. 2011.

GUIMARÃES, Deocleciano Torrieri.

Dicionário técnico jurídico. 9. ed. São Paulo: Rideel, 2007.

JORGE NETO, Francisco Ferreira; CAVALCANTE, Jouberto de Quadros Pessoa. Direito do Trabalho - Tomo II. 5. ed. Rio de Janeiro: Lumen Juris, 2010.

LOPES, Édina Aparecida. Flexibilização e desregulamentação das normas trabalhistas. Revista Judicare, Mato Grosso, jun. 2014. Disponível em: http://ienomat.com.br/revista/index.php/judicare/ar ticle/view/69/193. Acesso em: 25 abr 2015.

LOPES, Otávio Brito. Limites Constitucionais à Negociação Coletiva. Revista Jurídica Virtual. Brasília, fev. 2000. Disponível em: http://www.planalto.gov.br/ccivil_03/revista/Rev_09 /neg_coletiva_Otavio.htm. Acesso em 08 mai. 2015.

MACHADO, José Alexandre. A flexibilização dos direitos trabalhisas e a terceirização: aspectos destacados. Monografia (Graduação) Universidade do Vale do Itajaí - UNIVALI, São José, SC, 2008. 
MAGANO, Octavio Bueno. Manual de Direito do Trabalho - Direito Tutelar do Trabalho. 2. ed. São Paulo: LTR, 1991.

MARQUES, Fabíola. Direito do Trabalho. 8. ed. São Paulo: Atlas, 2013.

MARTINS, Luísa Gomes. O princípio da proteção em face da flexibilização dos direitos trabalhistas. Dissertação (Mestrado). Universidade de São Paulo, SP, 2010.

MARTINS, Sérgio Pinto. A terceirização e o Direito do Trabalho. 10. ed. rev. e ampl. São Paulo: Atlas, 2010, p. 26

MARTINS, Sérgio Pinto. Direito do Trabalho. 30. ed. São Paulo: Atlas, 2014.

NASCIMENTO, Amauri Mascaro. Curso de direito do trabalho. 14. ed. São Paulo: Saraiva, 2013.

MARTINS, Amauri Mascaro. Iniciação ao direito do trabalho. 39. ed. São Paulo: LTr, 2014.

PEREZ, Rosalba Maria Barros. A flexibilização das normas trabalhistas no Brasil à Luz da globalização. Monografia (Especialização). Universidade de Caxias do Sul. Rio Grande do Sul, 2007.
RESENDE, Júlia Mendonça de. ZAPATA, Daniela Lage Mejia. Limites jurídicos da negociação coletiva trabalhista. Letras Jurídicas, Belo HorizonteMG, 20 de mai. de 2014. Disponivel em: < http://npa.newtonpaiva.br/letrasjuridicas $/$ ? $=98>$. Acesso em: 21 de mai. de 2015.

SALGADO, Gisele Mascarelli. A Flexibilização Jurídica da Jornada de Trabalho. Universo Jurídico, Juiz de Fora, ano XI, 26 de mar. de 2009.

Disponivel em:

$<$

http://uj.novaprolink.com.br/doutrina/6147/a_flexib ilizacao_juridica_da_jornada_de_trabalho $>$. Acesso em: 21 de mai. de 2015.

SOARES, Fernanda Heloisa Macedo; MASSINE, Maiara Cristina Lima Massine. A flexibilização do Direito do Trabalho e a Constituição Federal de 1988. XIX Encontro Nacional do CONPEDI. Anais. Fortaleza-CE, 2010.

XAVIER, Alessandra Feitosa. Flexibilização das leis trabalhistas. Monografia (Especialização) Universidade Cândido Mendes. Rio de Janeiro, 2012 